\title{
ENCONTRO DE CRIADOURO NATURAL DE AEDES (STEGOMYIA) ALBOPICTUS (SKUSE), ESTADO DE SÃO PAULO, BRASIL
}

\section{Almério de Castro Gomes* Gisela R.A.M. Marques**}

A reinfestação do Brasil pelo Aedes aegypti ocorreu duas décadas passadas e a este fato somase a mais recente presença de Aedes albopictus, cuja identificação inicial foi feita por Forattini ${ }^{2}$ (1986). No Estado de São Paulo esse mosquito foi primeiramente detectado por Brito ${ }^{1}$ e col. (1986) no Município de Areias, regiåo do Vale do Paraíba. Sucessivos outros encontros estão anotados na Regional da Superitendência de Controle de Endemias (SUCEN) - Taubaté; todavia, todos eles referem-se a criadouros artificiais $e$ internódio de bambu ${ }^{* * *}$. Em abril de 1988, em visita às áreas de ocorrência de Ae.albopictus, naquela região, coletou-se água de oco de duas árvores denominadas flambuaiã (Delonix regia), na localidade de Quintal da Manoela, chácara situada apenas $4,0 \mathrm{~km}$ de distância do perímetro urbano da cidade de Tremembé (Fig.). O exame desse material revelou a presença de 19 larvas e 5 pupas de Ae. albopictus. Esse encontro reveste-se de importância epidemiológica por caracterizar hábito silvestre da cepa importada; possibilitar expansão rápida de sua distribuição; ser apenas parcialmente afetado pelo programa de controle de Aedes realizado pela SUCEN, e conseqüente potencial de elevação do risco de ocorrência do dengue na região. Ressalta-se ainda que devido ao caráter singular desta informação em nosso meio há necessidade imediata de estudos da biologia e do comportamento dessa espécie.

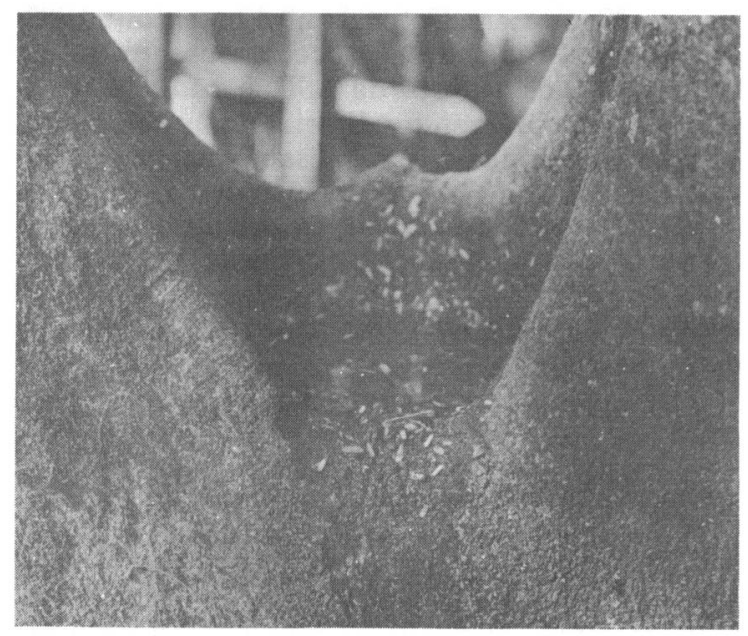

Figura. - Criadouro de Ae.albopictus em oco de árvore, Município de Tremembé, SP, Brasil

\section{AGRADECIMENTOS}

Agradecemos aos membros da Diretoria da SUCEN - Regional Taubaté, por ter proporcionado a oportunidade desta descoberta.

\section{REFERÊNCIAS BIBLIOGRÁFICAS}

BRITO, A. de: MARQUES, G.R.A.M.; MARQUES, C. A.; TUBAKI, R. M. Primeiro encontro de Aedes (Stegomyia) albopictus (Skuse) no Estado de São Paulo, Brasil. Rev. Saúde públ., S. Paulo 20:489, 1986.
FORATTINI, O. P. Identificação de Aedes (Stegomyia) albopictus (Skuse) no Brasil. Rev. Saúde públ., S. Paulo, 20: $244-5,1986$.

Recebido para publicaçâo em 31/5/1988 Aprovado para publicaçäo em 2/6/1988

- Departamento de Epidemiologia da Faculdade de Saúde Pública da Universidade de São Paulo - Av. Dr. Arnaldo, 715 - 01255 - São Paulo, SP - Brasil.

* Superintedência de Controle de Endemias (SUCEN) - Av. 9 de Julho, 372 - 12100 - Taubaté, SP - Brasil.

* * Informação pessoal de Ana Cláudia C.L. Khuriyeh - Diretora da Regional da Superintendência de Controle de Endemias (SUCEN) - Taubaté, SP - Brasil. 